・书评・

\title{
《温州植物志》，展示了市级植物志的价值
}

\author{
马克平 ${ }^{*}$ \\ (中国科学院植物研究所植被与环境变化国家重点实验室, 北京 100093)
}

\section{Flora of Wenzhou, a practical demo for local flora in China}

Keping Ma*

State Key Laboratory of Vegetation and Environmental Change, Institute of Botany, Chinese Academy of Sciences, Beijing 100093

在《中国植物志》和 Flora of China 等全国性 志书以及《浙江植物志》等省级志书出版之后, 是 否有必要继续编写市级植物志? 《温州植物志》的 编研实践给出了肯定的答案。丁炳扬和金川主编的 五卷本《温州植物志》于 2017 年由中国林业出版 社正式出版发行, 全书 358 万字, 是近百年来温州 植物资源调查和分类研究的系统总结。全书分概 论、各论和附录三部分: “概论”简要论述温州的自然 环境、植物研究简史、植物区系、植物资源的现状 与评价、植物资源保护和利用对策等; “各论”按分类 系统记载温州已知的野生和归化的维管束植物(即 偋类植物、裸子植物和被子植物), 包括科属种检索 表, 以及名称、形态特征、产地与生境和主要用途 等, $80 \%$ 以上的种类附有实地拍摄的彩色照片。“各 论”记载的野生维管植物共 210 科 1,035 属 2,544 种 36 亚种 178 变种(不包括存疑种)。综观《温州植物 志》, 有几个突出的特点:

第一, 基本摸清了温州植物多样性家底, 书中 记载了近年在温州发现的新种和新记录属种共 281 个, 包括新种 5 个, 浙江新记录属 10 个, 浙江新记 录种 37 个(含种下分类群, 以下同), 温州新记录属 29 个, 温州新记录种 200 个(附录 1)。这些信息在全 国或者省级植物志难以找到, 至少大部分信息是没 有记载的。

第二, 植物分布信息更加翔实, 县级分布信息 基本完整, 而且通过温州野生植物网站提供了乡镇 级分布信息，这是其他植物志书很少见到的。

第三，传统印刷版与在线的温州野生植物网站
相互补充，建立了新的模式。这与笔者 2017 年针对 省级植物志编研的建议类似(马克平, 2017)。该网站 (http://www.wzflora.net/)已于 2014 年上线, 可以提 供系统浏览，按科属、物种、分布、用途 4 种方式 检索(或交互检索), 以县或乡镇为单位查询植物科 属种的数目, 或各类用途植物的种类, 而且每种植 物都有以乡镇为单位的分布图, 非常实用, 日均访 问达三四千人次。

第四，温州是华东与华南植物区系分界线的一 部分，在中国植物区系区划中占有重要地位，兼具 中国植物区系分区的浙南山地亚地区(III D9c)和闽 南山地亚地区(III D11a)的植物区系成分(陈灵芝, 2014)。温州陆地面积占浙江的 $11.6 \%$, 但却涵盖了 浙江种子植物约 $60 \%$ 的属种，其中属为 $71.3 \%$ $(958 / 1,344)$, 种为 $56.8 \%(2,460 / 4,330)$, 浙江省的数 据参考郑朝宗等(2005)。对温州植物进行深入的调 查与分析，是对浙江省植物志的有益补充。

第五, 海岛植物区系调查获取新资料。温州地 处浙江东南沿海, 全市海域面积 1.1 万 $\mathrm{km}^{2}$, 有大 小海岛 700 多个。经过多次野外调查，已经发现岛 屿生长的植物 600 多种, 其中温州或浙江新记录植 物 20 多种(陈秋夏和王金旺, 2017)。而且, 多次调查 搜集的这 600 多种植物的分布信息，对于浙江省植 物志等的更新都是十分重要的参考资料。

第六，工作基础扎实。除系统整理和充分利用 已有植物标本和文献外, 项目组历时 6 年多, 先后 前往全市 55 个地点, 进行了 12 次大型考察、230 多次小型考察、13 次海岛调查, 采集标本 3.8 万余

\footnotetext{
* 通讯作者 Author for correspondence. E-mail: kpma@ibcas.ac.cn
} 
号, 拍摄照片 5.8 万余张, 对温州植物资源进行了 全面的系统调查, 参加者近 900 人次, 积累了翔实 的第一手资料。

第七, 在内容上, 形态描述更加简洁且突出主 要鉴别特征, 80\%的物种配有彩色照片、研究历史评 述、采集于温州的植物模式标本名录、针对保护与 利用的需求做出的分析, 都是本套志书比较有特色 的地方。

第八, 大胆启用年轻人, 重视年轻分类学队伍 的培养。在温州植物志中承担卷主编或副主编的年 轻分类学工作者有 7 位, 陶正明(浙江省亚热带作物 研究所)为第二卷主编、周庄(浙江省亚热带作物研 究所)为第三卷主编, 陈秋夏(浙江省亚热带作物研 究所)、王金旺(浙江省亚热带作物研究所)、吴棣飞 (温州市公园管理处)、熊先华(中国科学院成都生物 研究所)和张豪(浙江省乐清中学)作为卷副主编。

虽然没有时间认真阅读全书, 但也发现几处存 在问题的地方: (1)有的表述不够确切, 如“植物区系, 即一定区域内植物分类单位(科、属、种等)的总和” (P11), 以及“北平研究院(现中国科学院的前身)” (P5); (2)有几处校对错误, 如两处植物学家的名字 拼写错误, “胡先啸” (前言第二自然段)、“钱崇澎”
(P5); (3)缺少温州植物空间分布格局的分析。

市级植物志如何做? 《温州植物志》的经验值 得借鉴。市县级植物志的编研和出版发行, 为地方 植物多样性保护和利用提供了丰富可靠的信息，值 得大力提倡和鼓励。

\section{参考文献}

Chen LZ (2014) Flora and Vegetation Geography of China. Science Press, Beijing. (in Chinese) [陈灵芝 (2014) 中国 植物区系与植被地理. 科学出版社, 北京.]

Chen QX, Wang JW (2017) Island Flora of Wenzhou. China Forestry Publishing House, Beijing. (in Chinese) [陈秋夏, 王金旺 (2017) 温州海岛植物. 中国林业出版社, 北京.]

Ding BY, Jin C (2017) Flora of Wenzhou (Vols. 1-5). China Forestry Publishing House, Beijing. (in Chinese) [丁炳扬, 金川 (2017) 温州植物志(1-5 卷). 中国林业出版社, 北 京.]

Ma KP (2017) Revised version of Flora of Jiangsu with refreshing additions. Biodiversity Science, 25, 914. (in Chinese) [马克平 (2017) 《江苏植物志》修订再版, 令人耳目 一新. 生物多样性, 25, 914.]

Zheng CZ (2005) Keys of Seed Plants in Zhejiang, China. Zhejiang Science and Technology Publishing House, Hangzhou. (in Chinese) [郑朝宗 (2005) 浙江种子植物检索鉴定 手册. 浙江科学技术出版社, 杭州.]

\section{附录 Supplementary Material}

附录1 《温州植物志》编研过程中发现的新种与新记录(温州大学丁炳扬整理)

Appendix 1 New species and records of vascular plants found in Wenzhou since 2010 (Prepared by Bingyang Ding from Wenzhou University)

http://www.biodiversity-science.net/fileup/PDF/2018003-1.pdf 
马克平. 《温州植物志》, 展示了市级植物志的价值. 生物多样性, 2017, 25 (12): 1350-1351.

http://www.biodiversity-science.net/CN/10.17520/biods.2018003

\section{附录1《温州植物志》编研过程中发现的新种与新记录(温州大学丁炳扬整理)}

Appendix 1 New species and records of vascular plants found in Wenzhou since 2010 (Prepared by Bingyang Ding from Wenzhou University)

在《温州植物志》编研过程中发现的新种和新记录共 281 个, 包括新种 5 个, 浙江新记录属 10 个, 浙江新记录种 37 个(含种下分类群, 以下同), 温州新记录属 29 个, 温州新记录种 200 个。

\section{(一)新种 (5 种)}

1. 坤俊景天 Sedum kuntsunianum X. F. Jin, S. H. Jin \& B. Y. Ding (景天科)

2. 浙南茜草 Rubia austrozhejiangensis Z. P. Lei, Y. Y. Zhou \& R. W. Wang (茜草科)

3. 细嗀薹草 Carex tenuirostrata X. F. Jin, S. H. Jin \& D. F. Wu (莎草科)

4. 雁荡山薹草 Carex yandangshanica C. Z. Zheng \& X. F. Jin (莎草科)

5. 木本牛尾菜 Smilax ligneoriparia C. X. Fu et P. Li (百合科)

\section{(二)浙江新记录属(10 属)}

1. 白杪椤属 Sphaeropteris Bernh. (杪椤科)

2. 黄细心属 Boerhavia Linn. (紫茉莉科)

3. 柊属 Ziziphus Mill. (鼠李科) 原杳属记录的菄为栽培种

4. 山香属 Hyptis Jacq. (唇形科) 归化植物

5. 刺芯草属 Pogostemon Desf. (唇形科)

6. 野甘草属 Scoparia Linn. (玄参科) 归化植物

7. 墨苜宿属 Richardia Linn. (茜草科) 归化植物

8. 小丽草属 Coelachne R. Br. (禾本科)

9. 吻兰属 Collabium Blume (兰科)

10. 对叶兰属 Neottia Guettard (兰科)

\section{(三)浙江新记录种(37 种)}

1. 小叶海金沙 Lygodium microphyllum (Cav.) R. Br. (海金沙科)

2. 杪椤 Alsophila spinulosa (Wall. ex Hook.) R. M. Tryon (杪椤科)

3. 笔筒树 Sphaeropteris lepifera (Hook.) R. M. Tryon (杪椤科)

4. 异裂短肠硕 Allantodia laxifrons (Rosenst.) Ching (蹄盖硕科)

5. 倒卵伏石蕨 Lemmaphyllum microphyllum var. obovatum (Harr.) C. Chr. (水龙骨科)

6. 匍匐黄细心 Boerhavia repens Linn. (紫茉莉科)

7. 滇刺冭 Ziziphus mauritiana Lamarck (鼠李科)

8. 乌头叶蛇葡萄 Ampelopsis aconitifolia Bunge (葡萄科)

9. 掌裂草葡萄 Ampelopsis aconitifolia var. palmiloba (Carr.) Rehd. (葡萄科)

10. 毛枝蛇葡萄 Ampelopsis rubifolia (Wall.) Planch. (葡萄科)

11. 角花乌蔹莓 Cayratia corniculata (Benth.) Gagnep. (葡萄科)

12. 肉穗草 Sarcopyramis bodinieri Levl. et Vaniot(野牡丹科)

13. 山白前 Cynanchum fordii Hemsl. (夢摩科)

14. 原野菟丝子 Cuscuta campestris Yuncker (旋花科) 外来归化种

15. 台湾附地菜 Trigonotis formosana Hayata (紫草科)

16. 山香 Hyptis suaveolens (Linn.) Poit. (唇形科) 外来归化种

17. 水珍珠菜 Pogostemon auricularius (Linn.) Hassk. (唇形科)

18. 水茄 Solanum torvum Swartz (茄科) 外来归化种

19. 大叶石龙尾 Limnophila rugosa (Roth) Merr. (玄参科)

20. 野甘草 Scoparia dulcis Linn. (玄参科) 外来归化种

21. 蚂蝗七 Chirita fimbrisepala Hand.-Mazz. (苦菅苔科) 
马克平. 《温州植物志》, 展示了市级植物志的价值. 生物多样性, 2017, 25 (12): 1350-1351.

http://www.biodiversity-science.net/CN/10.17520/biods.2018003

22. 早田氏爵床 Justicia hayatae Yamamoto (爵床科)

23. 疏花车前 Plantago asiatica ssp. erosa (Wall.) Z. Y. Li (车前科)

24. 短小蛇根草 Ophiorrhiza pumila Champ. ex Benth. (茜草科)

25. 墨苜宿 Richardia scabra Linn. (茜草科) 外来归化种

26. 钮子瓜 Zehneria bodinieri (Lévl.) W. J. de Wilde et Duyfjes (葫芦科)

27. 小丽草 Coelachne simpliciuscula (Wight et Arn. ex Steud.) Munro ex Benth. (禾本科)

28. 镰形觡茅 Dimeria falcata Hack. (禾本科)

29. 硬直黑麦草 Lolium rigidum Gaudin (禾本科) 外来归化种

30. 显异荎草(鼠尾薹草) Carex eminens Nees (莎草科)

31. 耳苍鸭跖草 Commelina auriculata Blume (鸭跖草科)

32. 节节草(竹节菜) Commelina diffusa Burm. f. (鸭跖草科)

33. 趐距虾脊兰 Calanthe aristulifera Reichb. f. (兰科)

34. 台湾吻兰 Collabium formosanum Hayata (兰科)

35. 绿花斑叶兰 Goodyera viridiflora (Blume) Blume (兰科)

36. 日本对叶兰 Neottia japonica (Bl.) Szlach. (兰科)

37. 香港绶草 Spiranthes hongkongensis S. Y. Hu et Barretto (兰科)

(四)温州新记录属(29 属)

1. 南芥属 Arabis Linn. (十字花科)

2. 播娘蒿属 Descurainia Webb et Berth. (十字花科)

3. 旗杆芥属 Turritis Linn. (十字花科)

4. 常山属 Dichroa Lour. (虎耳草科)

5. 金缕梅属 Hamamelis Linn. (金缕梅科)

6. 千斤拔属 Flemingia Roxb. ex Ait. (豆科)

7. 猫乳属 Rhamnella Miq.(鼠李科)

8. 俞藤属 Yua C. L. Li (葡萄科)

9. 梭罗树属 Reevesia Lindl. (梧桐科)

10. 羊角芹属 Aegopodiun Linn. (伞形科)

11. 报春花属 Primula Linn. (报春花科)

12. 尖帽花属 Mitrasacme Labill. (马钱科)

13. 䯷药草属 Sinopogonanthera H. W. Li (唇形科)

14. 台闽苣苔属 Titanotrichum Soler. (苦苣苔科)

15. 菊芹属 Erechtites Raf. (菊科)

16. 银胶菊属 Parthenium Linn. (菊科) 归化植物

17. 碱苑属 Tripolium Nees (菊科) 植物志未标记

18. 川蔓藻属 Ruppia Linn. (眼子菜科)

19. 假牛鞭草属 Parapholis C. E. Hubb. (禾本科)

20. 束尾草属 Phacelurus Griseb. (禾本科)

21. 裂颖茅属 Diplacrum R. Br. (莎草科)

22. 金刚大属 Croomia Torr. ex Torr. et A. Gray (百部科)

23. 头芯兰属 Cephalanthera L. C. Rich. (兰科)

24. 盆距兰属 Gastrochilus D. Don (兰科)

25. 天麻属 Gastrodia R. Br. (兰科)

26. 旗唇兰属 Kuhlhasseltia J. J. Smith (兰科)

27. 兒被兰属 Neottianthe (Reichb. f.) Schltr. (兰科)

28. 山兰属 Oreorchis Lindl. (兰科) 
马克平. 《温州植物志》, 展示了市级植物志的价值. 生物多样性, 2017, 25 (12): 1350-1351.

http://www.biodiversity-science.net/CN/10.17520/biods.2018003

29. 带叶兰属 Taeniophyllum Bl. (兰科)

(五)温州新记录种(200 种)

1. 阔片乌蕨 Sphenomeris biflora (Kaulf.) Tagawa (鳞始蕨科)

2. 灰背铁线蕨 Adiantum myriosorum Bak. (铁线硕科)

3. 异裂短肠蕨 Allantodia laxifrons (Rosent.) Ching (蹄盖蕨科)

4. 长根金星彍 Parathelypteris beddomei (Bak.) Ching (金星痰科)

5. 紫柄硕 Pseudophegopteris pyrrhorhachis (Kunze) Ching (金星蕨科)

6. 大片复叶耳䕋 Arachniodes cavalerii (Christ) Ohwi (鳞毛蕨科)

7. 紫云山复叶耳硕 Arachniodes ziyunshanensis Y. T. Hsieh (鳞毛蕨科)

8. 中华鳞毛蒴 Dryopteris chinensis (Bak.) Koidz. (鳞毛蕨科)

9. 宜昌鳞毛蕨(顶羽鳞毛蕨) Dryopteris enneaphylla (Baker) C. Chr. (鳞毛蕨科)

10. 裸叶鳞毛蕨 Dryopteris gymnophylla (Baker) C. Chr. (鳞毛硕科)

11. 狭顶鳞毛蕨 Dryopteris lacera (Thunb.) O. Kuntze (鳞毛蕨科)

12. 无柄鳞毛蕨 (钝齿鳞毛蕨) Dryopteris submarginata Rosenst. (鳞毛蕨科)

13. 黄山鳞毛蕨 Dryopteris whangshangensis Ching (鳞毛蕨科)

14. 前原耳蕨 Polystichum mayebarae Tagawa(鳞毛蕨科)

15. 棕鳞耳硕 Polystichum polyblepharum (Roem. ex Kuntze) C. Presl (鳞毛硕科)

16. 相近石韦 Pyrrosia assimilis (Baker) Ching (水龙骨科)

17. 刺叶栋 Quercus spinosa David ex Franch. (壳斗科)

18. 黑弹树 Celtis bungeana Bltcme (榆科)

19. 楼梯草 Elatostema involucratum Franch. et Sav. (寽麻科)

20. 曲毛赤车 Pellionia retrohispida W. T. Wang (菖麻科)

21. 柔茎蓼 Polygonum kawagoeanum Makino(P. tenellum var. micranthum (Meisn.) C. Y. Wu (蓼科)

22. 小花蓼 Polygonum muricatum Meisn. (蓼科)

23. 暗果春蓼 Polygonum persicaria var. opacum (Sam.) A. J. Li (苶科)

24. 疏花苶 Polygonum praetermissum Hook. f. (蓼科)

25. 戟叶蓼 Polygonum thunbergii Sieb. et Zucc.

26. 长刺酸模 Rumex trisetifer Stokes (蓼科)

27. 灰绿藜 Chenopodium glaucum Linn. (菉科)

28. 南方碱蓬 Suaeda australis (R. Br.) Moq. (藜科)

29. 碱蓬 Suaeda glauca (Bunge) Bunge (藜科)

30. 西欧蝇子草 Silene gallica Linn. (石竹科)

31. 舟柄铁线莲 Clematis dilatata Péi (毛茛科)

32. 刺果毛茛 Ranunculus muricatus Linn. (毛茛科)

33. 五月瓜藤 Holboellia angustifolia Wall. (木通科)

34. 野木瓜 Stauntonia chinensis DC. (木通科)

35. 假豪猪刺(拟豪猪刺) Berberis soulieana Schneid. (小檗科)

36. 景宁木兰 Magnolia sinostellata P. L. Chiu et Z. H. Chen (木兰科)

37. 三桠乌药 Lindera obtusiloba Bl. (樟科)

38. 匍匐南芥 Arabis flagellosa Miq. (十字花科)

39. 心叶碎米荠 Cardamine limprichtiana Pax (十字花科)

40. 播娘蒿 Descurainia sophia (Linn.) Webb ex Prantl (十字花科)

41. 蓝花子 Raphanus sativus var. raphanistroides (Makino) Makino (十字花科)

42. 旗杆芥 Turritis glabra Linn. (十字花科)

43. 河岸阴山荠(河岸泡果荠) Yinshania rivulorum (Dunn) Al-Shehbaz et al. (十字花科)

44. 藓状景天 Sedum polytrichoides Hemsl. (景天科)

45. 肾莒金腰 Chrysosplenium delavayi Franch. (虎耳草科) 
马克平. 《温州植物志》, 展示了市级植物志的价值. 生物多样性, 2017, 25 (12): 1350-1351.

http://www.biodiversity-science.net/CN/10.17520/biods.2018003

46. 日本金腰 Chrysosplenium japonicum (Maxim.) Makino (虎耳草科)

47. 长江溲疏 Deutzia schneideriana Rehd. (虎耳草科)

48. 常山 Dichroa febrifuga Lour. (虎耳草科)

49. 柔毛钻地风 Schizophragma molle (Rehd.) Chun (虎耳草科)

50. 䓥树 Altingia chinensis (Champ.) Oliv. ex Hance (金缕梅科)

51. 蚊母树 Distylium racemosum Sieb. et Zucc. (金缕梅科)

52. 金缕梅 Hamamelis mollis Oliv. (金缕梅科)

53. 大叶早樱 Cerasus subhirtella (Miq.) Sok. (蓄薇科)

54. 三裂中南悬钩子 Rubus grayanus var. trilobatus Yü et Lu (萻薇科)

55. 无腺白叶莓 Rubus innominatus var. kuntzeanus (Hemsl.) Bailey (蓄微科)

56. 含羞草决明 Cassia minmosoides Linn. (豆科)

57. 广西紫荆 Cercis chuniana Metc. (豆科)

58. 三点金 Desmodium triflorum (Linn.) DC. (豆科)

59. 千斤拔 Flemingia prostrata Rox. (豆科)

60. 短梗胡枝子 Lespedeza cyrtobotrya Miq. (豆科)

61. 密花崖豆藤 Millettia congestiflora T. Chen (豆科)

62. 通奶草 Euphorbia hypericifolia Linn. (大戟科)

63. 小叶大戟 Euphorbia makinoi Hayata (大戟科)

64. 落萝叶下珠 Phyllanthus flexuosus (Sieb. et Zucc.) Muell.-Arg. (大戟科)

65. 白背麸杨 Rhus hypoleuca Champ. ex Benth. (漆树科)

66. 青敖杨 Rhus potaninii Maxim. (漆树科)

67. 光枝刺叶冬青 Ilex hylonoma Hu et T. Tang var. glabra S. Y. Hu (冬青科)

68. 全缘冬青 Ilex integra Thunb. (冬青科)

69. 腺萼南蛇藤(东南南蛇藤) Celastrus punctatus Thunb. (卫矛科)

70. 陈谋卫矛 Euonymus chenmoui Cheng (卫矛科)

71. 海岸卫矛 Euonymus tanakae Maxim. (卫矛科)

72. 淡黄绿凤仙花 Impatiens chloroxantha Y. L. Chen (凤仙花科)

73. 黄岩凤仙花 Impatiens huangyanensis X. F. Jin et B. Y. Ding (凤仙花科)

74. 天目山风仙花 Impatiens tienmushanica Y. L. Chen (凤仙花科)

75. 管茎凤仙花 Impatiens tubulosa Hemsl. (凤仙花科)

76. 猫乳(鼠矢柊) Rhamnella franguloides (Maxim.) Weberb. (鼠李科)

77. 两色冻绿 Rhamnus crenata var. discolor Rehd. (鼠李科)

78. 皱叶鼠李 Rhamnus rugulosa Hemsl. (鼠李科)

79. 葎叶蛇葡萄 Ampelopsis humulifolia Bunge (葡萄科)

80. 华东葡萄 Vitis pseudoreticulata W. T. Wang (葡萄科)

81. 小叶葡萄 Vitis sinocinerea W. T. Wang (葡萄科)

82. 俞藤(粉叶爬山虎) Yua thomsonii (Laws.) C. L. Li (葡萄科)

83. 短毛椴 Tilia chingiana Hu et W. C. Cheng (椴树科)

84. 华东椴 Tilia japonica Simonk. (椴树科)

85. 密花梭罗 Reevesia pycnantha Ling (梧桐科)

86. 京梨猕猴桃 Actinidia callosa var. henryi Maxim. (猕猴桃科)

87. 梅叶猕猴桃 Actinidia macrosperma C. F. Liang var. mumoides C. F. Liang (狝猴桃科)

88. 安息香猕猴桃 Actinidia styracifolia C. F. Liang (狝猴桃科)

89. 粗齿堇菜(犁头叶堇菜) Viola magnifica C. J. Wang et X. D. Wang (堇菜科)

90. 紫背堇菜 Viola violacea Makino (堇菜科) 
马克平. 《温州植物志》, 展示了市级植物志的价值. 生物多样性, 2017, 25 (12): 1350-1351.

http://www.biodiversity-science.net/CN/10.17520/biods.2018003

91. 耳基水苋 Ammannia auriculata Will. (千屈菜科)

92. 多花水苋 Ammannia multiflora Roxb. (千屈菜科)

93. 腺茎柳叶菜 Epilobium brevifolium D. Don ssp. trichoneurum (Hausskn.) P. H. Raven (柳叶菜科)

94. 黄花月见草 Oenothera glazioviana Micheli (柳叶菜科) 归化植物

95. 食用土当归 Aralia cordata Thunb. (五加科)

96. 柔毛土当归(柔毛龙眼独活) Aralia henryi Harms (五加科)

97. 湘桂羊角芹 Aegopodium nandelii Wolff (伞形科)

98. 岩茴香 Ligusticum tachiroei (Franch. et Sav.) Hiroe et Constance (伞形科)

99. 红毛过路黄 Lysimachia rufopilosa Y. Y. Fang et C. Z. Cheng (报春花科)

100. 毛莨叶报春(堇叶报春) Primula cicutariifolia Pax (报春花科)

101. 柳叶蓬莱葛 Gardneria lanceolata Rehd. et Wils. (马钱科)

102. 水田白 Mitrasacme pygmaea R. Br. (马钱科)

103. 黄山龙胆 Gentiana delicate Hance (龙胆科)

104. 溪黄草 Isodon serra (Maxim.) Kudô (唇形科)

105. 中华香简草 Keiskea sinensis Diels (唇形科)

106. 杭州荠苛 Mosla hangchowensis Matsuda (唇形科)

107. 曲茎假糙苏 Paraphlomis foliata (Dunn) C. Y. Wu et H. W. Li (唇形科)

108. 浙江黄芩 Scutellaria chekiangensis C. Y. Wu (唇形科)

109. 光紫黄芩 Scutellariala laeteviolacea Koidz. (唇形科)

110. 短促京黄芩 Scutellaria pekinensis var. transitra (Makino) H. Hara ex H. W. Li (唇形科)

111. 中间髵药草 Sinopogonanthera intermedia (C. Y. Wu et H. W. Li) H. W. Li

112. 毛酸浆 Physalis philadelphica Lam. (茄科)

113. 喀西茄 Solanum aculeatissimum Jacq. (茄科) 外来归化种

114. 江西马先蒿 Pedicularis kiangsiensis Tsoong et Cheng f. (玄参科)

115. 大花旋蒴苣苔 Boea clarkeana Hemsl. (苦苣苔科)

116. 长瓣马铃苣苔 Oreocharis auricula (S. Moore) C. B. Clarke (苦苣苔科)

117. 大花石上莲 Oreocharis maximowiczii Clarke (苦苣苔科)

118. 台闽苣苔 Titanotrichum oldhamii (Hemsl.) Soler. (苦苣苔科)

119. 硬毛四叶葎 Galium bungei var. hispidum (Matsuda) Cufodontis (茜草科)

120. 狭叶桅子 Gardenia stenophylla Merrill (茜草科)

121. 柔垂烦草 Valeriana flaccidissima Maxim. (败酱科)

122. 湘桂栝楼(小花栝楼) Trichosanthes hylonoma Hand.-Mazz. (葫芦科)

123. 中华沙参 Adenophora sinensis A. DC. (桔梗科)

124. 穿叶异檐花 Triodanis perfoliata (Linn.) Nieuwland (桔梗科)

125. 滨蒿 Artemisia fukudo Makino (菊科)

126. 白莲蒿 Artemisia sacrorum Ledeb. (菊科)

127. 白花地胆草 Elephantopus tomentosus Linn. (菊科)

128. 梁子菜 Erechtites hieraciifolius (Linn.) Raf. ex DC. (菊科) 外来归化种

129. 费城飞蓬 Erigeron philadelphicus Linn. (菊科) 外来归化种

130. 大麻叶泽兰 Eupatorium cannabinum Linn. (菊科) 外来归化种

131. 细叶小苦荬 Ixeridium gracile (DC.) Pak et Kawano (菊科)

132. 毒莫苣 Lactuca seriola Torner (菊科) 外来归化种

133. 银胶菊 Parthenium hysterophorus Linn. (菊科) 外来归化种

134. 长花帚菊(卵叶帚菊) Pertya scandens (Thunb.) Sch.-Bip.

135. 心叶风毛菊 Saussurea cordifolia Hemsl. (菊科) 
马克平. 《温州植物志》, 展示了市级植物志的价值. 生物多样性, 2017, 25 (12): 1350-1351.

http://www.biodiversity-science.net/CN/10.17520/biods.2018003

136. 续断菊(花叶滇苦菜) Sonchus asper (Linn.) Hill. (菊科) 外来归化种

137. 碱苑 Tripolium pannonicum (Jacq.) Dobrocz. (菊科)

138. 川蔓藻 Ruppia maritima Linn. (眼子菜科)

139. 冠果草 Sagittaria guayanensis Kunth subsp. lappula (D. Don) Bojin (泽泻科)

140. 利川慈菇 Sagittaria lichuanensis J. K. Chen et H. Q. Wang (泽泻科)

141. 小慈姑(小叶慈菇) Sagittaria potamogetifolia Merr. (泽泻科)

142. 有尾水篎 Blyxa echinosoerma (Clarke) Hook. f. (水鳖科)

143. 罗氏黑藻 Hydrilla verticillata var. roxburghii Casp. (水鳖科)

144. 红哺鸡竹(红竹) Phyllostachys iridescens C. Y. Yao et S. Y. Chen (禾本科)

145. 早园竹 Phyllostachys propinqua McClure (禾本科)

146. 红边竹 Phyllostachys rubromarginata McClure (禾本科)

147. 䀧县苦竹 Pleioblastus juxianensis Wen (禾本科)

148. 实心苦竹 Pleioblastus solidus S. Y. Chen (禾本科)

149. 日本看麦娘 Alopecurus japonicus Steud. (禾本科) 外来归化种

150. 毛节野古草 Arundinella barbinodis Keng ex B. S. Sun et Z. H. Hu (禾本科)

151. 扁穗雀麦 Bromus catharticus Vahl (禾本科)

152. 止血马唐 Digitaria ischaemum (Presl) Miq. (禾本科)

153. 具脊觿茅 Dimeria ornithopoda ssp. subrobusta (Hack.) S. L. Chen et G. Y. Sheng (禾本科)

154. 秋画眉草 Eragrostis autumnalis Keng (禾本科)

155. 浙江柳叶箬 Isachne hoi Keng f. (禾本科)

156. 日本柳叶箬 Isachne nipponensis Ohwi (禾本科)

157. 鸭嘴草 Ischaemum aristatum var. glaucum (Honda) T. Koyama (禾本科)

158. 粗毛鸭嘴草 Ischaemum barbatum Retz. (禾本科)

159. 矶子草 Leptochloa panicea (Retz.) Ohwi (禾本科)

160. 多花黑麦草 Lolium multiflorum Lamk. (禾本科) 外来归化种

161. 日本莠竹 Microstegium japonicum (Miq.) Koidz. (禾本科)

162. 狭叶求米草 Oplismenus undulatifolius var. imbecillis (R. Brown) Hackel (禾本科)

163. 日本求米草 Oplismenus undulatifolius var. japonicus (Steud.) G. Koidz. (禾本科)

164. 假牛鞭草 Parapholis incurva (Linn.) C. E. Hubb. (禾本科)

165. 束尾草 Phacelurus latifolius (Steud.) Ohwi (禾本科)

166. 毛鼠尾粟 Sporobolus piliferus (Trin.) Kunth (禾本科)

167. 宜昌薹草 Carex ascotreta C. B. Clarke ex Franch. (莎草科)

168. 秋生薹草 Carex autumnalis Ohwi (莎草科)

169. 短芒薹草 Carex breviaristata K. T. Fu (莎草科)

170. 长囊臺草 Carex harlandii Boott (莎草科)

171. 日本臺草 Carex japonica Thunb. (莎草科)

172. 长嘴薹草 Carex longirostrata C. A. Mey. (莎草科)

173. 踠豆型薹草 Carex pisiformis Boott (莎草科)

174. 䊁叶臺草 Carex scabrifolia Steud. (莎草科)

175. 近头状薹草 Carex subcapitata X. F. Jin \& al. (莎草科)

176. 细穗薹草 Carex tenuispicula Tang ex S. Yun Liang (莎草科)

177. 藏薹草 Carex thibetica Franch. (莎草科)

178. 天目山薹草 Carex tianmushanica C. Z. Zheng \& X. F. Jin (莎草科)

179. 健壮薹草 Carex wahuensis C. A. Mey. ssp. robusta (Franch. et Sav.) T. Koyama (莎草科)

180. 长穗高秆莎草 Cyperus exaltatus Retz. var. megalanthus Kük. (莎草科) 
马克平. 《温州植物志》, 展示了市级植物志的价值. 生物多样性, 2017, 25 (12): 1350-1351.

http://www.biodiversity-science.net/CN/10.17520/biods.2018003
181. 裂颖茅 Diplacrum caricinum R. Br. (莎草科)
182. 宜昌飘拂草 Fimbristylis henryi C. B. Clarke (莎草科)
183. 海三棱蔍草 Scirpus $\times$ mariqueter Tang \& F. T. Wang (莎草科)
184. 金刚大(黄精叶钩吻) Croomia japonica Miq. (百部科)
185. 宽叶老鸦瓣(阔叶老鸦瓣) Tulipa erythronioides Baker (百合科)
186. 换锦花 Lycoris sprengeri Comes ex Baker (石蒜科)
187. 穿龙薯蓣(龙草薢) Dioscorea nipponica Makino (薯蓣科)
188. 头花水玉篗 Burmannia championii Thw. (水玉䈐科)
189. 宽翅水玉䙃 Burmannia nepalensis (Miers) J. D. Hooker (水玉䙃科)
190. 斑唇卷瓣兰 Bulbophyllum pectenveneris (Gagnep.) Seidenf. (兰科)
191. 银兰 Cephalanthera erecta (Thunb. ex A. Murray) Bl. (兰科)
192. 金兰 Cephalanthera falcata (Thunb. ex A. Murray) Bl. (兰科)
193. 中华盆距兰 Gastrochilus sinensis Z. H. Tsi (兰科)
194. 天麻 Gastrodia elata Bl. (兰科)
195. 裂瓣玉凤花 Habenaria petelotii Gagnep. (兰科)
196. 旗唇兰 Kuhlhasseltia yakushimensis (Yamamoto) Ormerod (兰科)
197. 二叶兒被兰 Neottianthe cucullata (Linn.) Schltr. (兰科)
198. 长叶山兰 Oreorchis fargesii Finet (兰科)
199. 筒距舌唇兰 Platanthera tipuloides (Linn. f.) Lindl. (兰科)
200. 带叶兰 Taeniophyllum glandulosum Bl. (兰科) 